\title{
Uma compreensão missiológica da covid-19
}

\section{JOHNNY RAMIREZ-JOHNSON ${ }^{1}$ MARCELO DIAS ${ }^{2}$}

\begin{abstract}
Resumo: A pandemia do novo coronavírus forçou as igrejas cristãs ao redor do mundo a revisitar sua autocompreensão fundamental e suas atividades. Por meio de lentes etnográficas, os pesquisadores analisaram reações e adaptações em face da covid-19 por parte de líderes religiosos do sul da Califórnia, Estados Unidos. Tendo um dos autores como participante-observador, o artigo inclui um estudo de caso da Igreja Adventista do Sétimo Dia Glendale City Church (GCC). Baseado no conceito de interseccionalidade, um quadro teórico para a compreensão de como as identidades e experiências combinadas de uma pessoa podem gerar vantagens e desvantagens, o artigo propõe a primazia da lógica epistêmica do amor segundo 1 Coríntios 13. Diante desse cenário, qual seria a compreensão missiológica apropriada da covid-19?
\end{abstract}

Palavras-Chave: Missiologia; interseccionalidade; eclesiologia; covid-19; Adventista do Sétimo Dia.

\section{A missiological understending from covid-19}

\begin{abstract}
The novel coronavirus pandemic forced Christian church around the world to revisit their fundamental self-understanding and activities. Through ethnographic lenses, the researchers analyze reactions and adaptations in face of covid-19 by religious leaders from Southern California, USA. Having one of the authors as an observant-participant, the article includes a case study of the Seventh-day Adventist Glendale City Church (GCC). Based on the concept of intersectionality, a theoretical framework to understand how one's identities and experiences combined produce advantages and disadvantages, the article proposes the primacy of the epistemic logic of love, according to 1 Corinthians 13. As per this scenario, what would be an appropriate missiological understanding of covid-19?
\end{abstract}

\footnotetext{
1 Doutor e Mestre em Educação pela Harvard University; Mestre em Escrituras Hebraicas e Arqueologia pela Andrews University; Bacharel em Teologia pelo Antillean College; Professor no Fuller Theological Seminary. E-mail: ramirez-johnson@fuller.edu

2 Doutor em Religião (Estudos Interculturais e Missiologia) pela Andrews University; MBA pela La Sierra University; Bacharel em Teologia pelo Centro Universitário Adventista de São Paulo e em Administração e Teologia pelo Union College; Professor no Centro Universitário Adventista de São Paulo. E-mail: marcelo.dias@unasp.edu.br
} 
Keywords: Missiology; intersectionality; ecclesiology; covid-19; Seventh-day Adventist.

\section{A covid-19 e a crise de adoração na quarentena}

Todd, nosso pastor sênior, convocou uma reunião urgente. "A cidade, o estado e o condado anunciaram que estão considerando uma quarentena para evitar a covid-19. Devemos proteger nossos membros mais idosos e cancelar os cultos?". Era uma pergunta retórica, pois todos sabíamos que o cancelamento de reuniões públicas seria obrigatório, especialmente para uma congregação composta principalmente por membros idosos; mas a decisão foi considerável.

Que tal transmitir o culto através do canal da Glendale City Church (GCC) no YouTube ou via Zoom, com vários participantes em casa? A pergunta era principalmente minha. A equipe pastoral, da qual faço parte como pastor voluntário, estava certa de que conduzir o culto a partir da igreja era essencial. "As pessoas se sentirão consoladas ao, pelo menos, ver o prédio", disse o nosso pastor administrativo. Invocando a academia, perguntei: "Mas, afinal, o que é adoração?".

Durante a quarentena por causa da pandemia, a expectativa era de que nossas finanças fossem devastadas. "Com pessoas adorando a partir de casa, como poderemos apelar pelos recursos?" (Não me lembro quem disse isso). "Como poderemos ter certeza de que as pessoas vão "participar" da adoração e "frequentar" os cultos?", silenciosamente, me perguntei. A igreja é uma organização voluntária - tudo é feito porque as pessoas participam. Definir a igreja não é uma tarefa simples. Ela é, entre outras compreensões, um fenômeno social relacionado ao seu contexto, tanto como causa, quanto como consequência. Defini-la, quando a mudança é o princípio orientador, torna a tarefa ainda mais desafiadora. Portanto, qual seria o contexto definidor da "igreja", hoje?

Esta pandemia, de dimensões sem precedentes, levou a uma reconfiguração caracterizada pelo isolamento social e a quarentena de praticamente todas as pessoas. Quase todos foram afetados não só no trabalho, mas também na educação, recreação e religião. Para evitar aglomerações, de forma geral, os templos religiosos suspenderam os cultos e as celebrações, orientaram especialmente os fiéis do grupo de risco a ficarem em casa e tiveram que se "reinventar" (JEFFERY, 2020).

Mas não foram só os cultos de adoração que mudaram. A coleta de dízimos e ofertas, as reuniões de oração, os estudos bíblicos, os concertos musicais, as mobilizações de solidariedade e até velórios e batismos tiveram que ser adaptados. No geral, as igrejas tiveram que se apresentar na internet, abraçar as mídias sociais, arriscar mudanças inovadoras e encarar a sua essência.

\section{A covid-19 é um sinal de nevasca ou da idade do gelo?}

Assumindo uma perspectiva positiva, as necessidades impostas pela mudança são boas notícias para a igreja, se ela prestar atenção ao que o Espírito Santo está fazendo. A atuação do Espírito Santo poderia ser analisada a partir dos jargões teológicos; em vez disso, este artigo segue as propostas de Crouch, Keilhacker e Blanchard (2020). Esses autores fornecem uma avaliação que pode abrir as portas para uma nova era na eclesiologia missional.

Em vez de gelo e eras geológicas, considere a história da igreja. A ideia de que a economia e a cosmologia dos deuses do Parthenon romano e grego sobreviveriam ao início da cristandade após o "batismo" de Constantino pode ser um bom paralelo para os dias atuais da covid-19. A conflagração de forças hoje é semelhante aos tempos constantinianos. No entanto, em vez de um 
novo Império Cristão nascer agora, observa-se como um vírus, mais as desigualdades raciais e econômicas e uma epistemologia pós-cristã (para citar apenas algumas das forças em jogo) desafiam o status quo da igreja, do governo e da chamada ordem mundial. Crouch, Keilhacker e Blanchard (2020) fornecem cinco pontos para calibrar sumariamente o foco que acaba por responder à pergunta principal da equipe pastoral: $\mathrm{O}$ que fazer com a igreja agora?

1. O novo coronavírus não é apenas algo para os líderes esperarem "passar” em alguns dias ou semanas. Em vez disso, é necessário tratar a covid-19 como uma nevasca econômica e cultural, um inverno e o início de uma "pequena era do gelo" - uma mudança única que provavelmente afetará vidas e organizações durante anos.

2. Devido à natureza complexa e interligada da sociedade e da economia, a maioria das empresas e organizações sem fins lucrativos está "praticamente falida", pois os pressupostos subjacentes que sustentaram essas organizações já não são verdadeiros.

3. A prioridade dos líderes deve ser deixar de lado a confiança em sua cartilha atual, o mais rápido possível, e escrever uma nova que honre sua missão e a das comunidades que servem, para aproveitar ao máximo os ativos da organização - pessoas, capital financeiro e social - apoiando-se em relacionamento e confiança.

4. O potencial criativo da esperança e da visão é incomparável neste momento, mas paradoxalmente, essa criatividade só estará totalmente disponível se também houver espaço para tristeza e lamento.

5. Isto está sendo escrito por amor aos líderes organizacionais cristãos e seu trabalho, com muita humildade, em um momento de considerável incerteza, e até com uma ponta de esperança de que Deus, em sua providência graciosa, operando milagrosamente através da habilidade humana neste momento, demonstre que a solução é mais fácil do que se vislumbra (CROUCH et al., 2020, online, tradução livre).

Esse último ponto enquadra todos os quatro anteriores e acrescenta um aspecto fundamental, com a expressão "por amor". O amor é a potência dos ensinamentos bíblicos. Um amor que, nas palavras da Bíblia, é liderado pelo Espírito Santo, o Espírito de Cristo: "O amor nunca perece; mas as profecias desaparecerão, as línguas cessarão, o conhecimento passará (1Co 13:8, NVI). O Espírito Santo, como criador da virtude do amor, parece estar convidando a igreja hoje a aderir à mudança.

Mudança é a palavra operativa por trás da mensagem de Crouch, Keilhacker e Blanchard (2020). Talvez a mais difícil de todas as formas de mudança seja aquela que é radical: "deixar de lado a confiança em sua cartilha atual” (CROUCH et al., 2020, online, tradução livre). Esse tipo de mudança é inquietante! Mas é isso que é preciso para amar. O objetivo não pode ser a sobrevivência, pois seria uma blasfêmia ao Espírito Santo que conduz a igreja. Quando "as suposições subjacentes que sustentaram sua organização não são mais verdadeiras" (CROUCH et al., 2020, online, tradução livre), os líderes são chamados a amar seus membros até a morte.

Hoje líderes que seguem o Espírito de Cristo devem esquecer as "profecias" denominacionais, porque, afinal de contas, essas profecias "desaparecerão". Os líderes segundo o Espírito Santo, que dá línguas, não devem mais priorizar esse dom, porque "línguas cessarão". Igrejas, como a GCC, que priorizam o conhecimento da Bíblia e a pureza doutrinária devem ser lembradas de que "o conhecimento passará" (1Co 13:8, NVI). Mas certamente não deve significar que as profecias, línguas e conhecimento devem ser esquecidos de vez, eles devem ser firmemente colocados sob a epistemologia e a hermenêutica do amor. 


\section{0 que é a igreja? Um estudo de caso}

A interseccionalidade, um quadro teórico para a compreensão de como as identidades e experiências combinadas de uma pessoa podem gerar vantagens e desvantagens (STEINMETZ, 2020), define a GCC há muito tempo. A cada sábado de manhã, essa igreja oferece lições de estudo bíblico, versículo por versículo, segundo interpretações tradicionais herdadas da cristandade. Ao mesmo tempo, realiza um encontro de diálogo, relaxamento e apoio mútuo que, muitas vezes, mas nem sempre, inclui um foco espiritual fornecido por um poema ou outra leitura inspiradora. Em uma terceira reunião, as pessoas estudam um livro - sobre diversos tópicos relacionados às agendas focadas na igreja - em ciclos de três meses.

O pastor sênior, em palavras que são um testemunho das guerras eclesiais de hoje entre as igrejas evangélicas, define a interseção dizendo frequentemente: "A maneira como tratamos os membros LGBTQ+ é o canário na mina de carvão ${ }^{3}$ do amor de uns pelos outros na nossa comunidade". Esta é uma Igreja Adventista do Sétimo Dia (IASD) que segue a política denominacional apesar de ter redefinido o termo "membro" de maneira mais inclusiva. O objetivo é usar termos eclesiásticos de maneira a evitar uma linguagem propositalmente excludente que, de alguma forma, poderia dividir as pessoas que frequentam os cultos. "Membro", conforme a definição da GCC, é "qualquer pessoa que se una conosco para pertencer à comunidade de crentes". Obviamente, em qualquer sábado, todos que estão na igreja, estão fazendo isso; assim, todos os participantes são vistos e referidos como membros.

Os sociólogos classificam "igreja” como uma instituição religiosa de afiliação voluntária e economia filantrópica; religião, por sua vez, tem sido definida como uma instituição cultural relacionada a crenças, rituais e sentimentos. "Instituição", no entanto, não é um termo muito bem-vindo na cultura pós-cristandade das gerações do milênio e $Z$, já que crenças e espiritualidade são vistas como divorciadas da organização religiosa.

Essa noção de "religião sem igreja" ainda é controversa. Muitos pregadores não apenas a criticam; mes-
mo as pessoas que a praticam, às vezes, preferem outros termos. Por exemplo, ouvi muitos americanos
dizerem: "Sou muito espiritual, mas nem um pouco religioso" - significando, entre outras coisas, que
estão muito interessados em ter uma conexão com "poderes superiores", com o significado da vida, e
outras coisas, mas não apoiam nenhum estabelecimento religioso para fazê-lo (SPICKARD, 2017, p. 2).

Como deveriam ser os cultos institucionais da quarentena da covid-19 na GCC? Assim como Willimon, em 1981, não via como definir igreja separada de suas manifestações institucionais, a equipe pastoral da GCC também não pode:

Mas o meu problema com a simplicidade da igreja institucional é que fui chamado exatamente para esta igreja, e não para outra: a igreja com seu número de membros em declínio e seu entusiasmo gasto, e o superintendente distrital que deseja relatórios três vezes melhores. (WILLIMON, 1981, p. 634-635).

O peso das demandas hierárquicas denominacionais e os vários compromissos financeiros se tornam particularmente agudos durante uma pandemia, quando os membros não podem se

3 Expressão idiomática que significa "sinal de alerta de que algo ou alguém está em perigo". 
reunir. Conseguirão os pastores, que seguem Jesus sob a influência do Espírito Santo, cumprir seu orçamento para despesas locais e/ou as remessas de dízimos denominacionais?

Três pontos fundamentais, apresentados por Branson e Martinez (2011), são relevantes. Primeiramente, o amor é definido nos relacionamentos, e esses relacionamentos são interculturais. "O amor de Deus pelo mundo, do qual devemos participar, está sempre nos chamando para uma vida intercultural". Em segundo lugar, as realidades interculturais do mundo, de uma internet intercultural e a de uma pandemia que vai e vem através das fronteiras fluidas já estão aqui. O novo coronavírus simplesmente as revelou, de uma forma óbvia para os negacionistas, que podem vê-la ou serem cegados por ela. O mundo é glocal, ou seja, é local e global ao mesmo tempo. Em terceiro lugar, essa realidade intercultural e interseccional (uma palavra que não era amplamente usada em 2011) deve ser vista pelo que é: "um presente de Deus e uma tarefa a ser adotada pelas igrejas de Deus” (BRANSON; MARTINEZ, 2011, online).

A interseccionalidade do mundo já era discutida em 2011. De fato, as palavras de Oscar Garcia-Johnson à época indicam isso: "O Pentecostes é a narrativa bíblica formativa que revela como o Espírito cruzou um meio cultural, respeitando, abraçando e afirmando suas várias e múltiplas histórias e identidades" (GARCIA-JOHNSON apud BRANSON; MARTINEZ, 2011, online). A interseccionalidade é o caminho do Espírito Santo e os dons do Espírito Santo são de natureza interseccional.

A definição de uma epistemologia do amor talvez possa ser mais bem compreendida por meio da leitura da Bíblia de maneira direta:

Ainda que eu fale as línguas dos homens e dos anjos, se não tiver amor, serei como o sino que ressoa ou como o prato que retine. Ainda que eu tenha o dom de profecia e saiba todos os mistérios e todo o conhecimento, e tenha uma fé capaz de mover montanhas, mas não tiver amor, nada serei. Ainda que eu dê aos pobres tudo o que possuo e entregue o meu corpo para ser queimado, mas não tiver amor, nada disso me valerá. (1Co 13:1-3, NVI).

$\mathrm{O}$ amor suplanta o poder de falar, mesmo as línguas dos anjos. $\mathrm{O}$ amor suplanta até mesmo o conhecimento dos mistérios, isto é, “todos os mistérios." O amor suplanta a fé, mesmo uma fé capaz de mover montanhas. $\mathrm{O}$ amor suplanta a generosidade, mesmo uma generosidade que não retém nada, incluindo dar a própria vida. $\mathrm{O}$ amor é a experiência mais sublime, central e além de todas as experiências humanas, mesmo quando essas experiências interseccionam com as realidades celestiais.

Interseccionalidade significa pelo menos duas coisas: afirmar a validade de histórias individuais em seus legítimos contextos “originais”. E, também, afirmar a necessidade de histórias divergentes - legítimas e legitimadas - para entrar em diálogo e interseccionar entre si. No entanto, a intersecção só pode acontecer sob o amor radical comunicado pelo Espírito Santo.

A virtude da interseccionalidade vem do abandono da necessidade e da urgência de estabelecer uma compreensão linear entre o que 1 Coríntios 13:8 chama de profecias, línguas e conhecimentos, colocando todos os três em equilíbrio com o amor. $\mathrm{O}$ amor supera todos os três.

Deus chama cada ser humano para agir com amor e ser em cada momento o melhor ser humano que essa pessoa possa ser. Isso é amor persuasivo. Para mim, isso significa que Deus não causou ou permitiu meu sofrimento. Os seres humanos fizeram escolhas que provocaram meu sofrimento. Eles pecaram. Deus não poderia ter feito uma intervenção como um grande deus ex-machina e me resgatado, mas, apesar de tudo, 
Deus, com amor persuasivo, os chamou para serem melhores do que eram. Eles não o ouviram. A percepção mais importante para mim, no entanto, foi de que Deus sofreu comigo. Eu nunca estive sozinho no meu sofrimento. $\mathrm{O}$ amor persuasivo de Deus estava comigo também, me chamando para ser melhor, para ser mais. Ao deixar de lado o que agora entendi como noções patriarcais de poder, incorporadas de maneiras particulares na noção de um Deus todo-poderoso que controla o universo, abracei um Deus imanente cujo amor nos chama a amar e que abre um futuro que não tem que ser determinado por domínio, hierarquia e controle, mas pode ser caracterizado pelo amor, recepção, multiplicidade e conexão (KIM; SHAW, 2018, p. xiii).

Conforme descrito por Kim e Shaw (2018), interseccionalidade é a virtude - o dom do Espírito Santo que coloca a epistemologia do amor sobre e acima de todas as outras definições epistêmicas para a verdade. É sobre e acima do controle do passado e do futuro, manifestado pela ênfase na verdade profética, igualmente superior às línguas que qualificam a experiência de alguém e definitivamente mais elevada do que o conhecimento que define todas as doutrinas da igreja. Como é possível adotar essa lógica epistêmica? Como se define a epistemologia do amor?

\title{
Oportunidades de serviço durante a pandemia da covid-19 - a ideologia epistêmica "certa"
}

Mercadante (2014) explica que a interseccionalidade estava presente antes da covid-19, mas as complicações da igreja de hoje ainda surpreendem. Por um lado, entrar em um prédio de igreja não é uma experiência semanal para a maioria das pessoas na América do Norte e na Europa Ocidental. Mesmo antes do novo coronavírus, as pessoas evitavam os prédios das igrejas; mas a pandemia da covid-19 padronizou esse fato para todos os americanos.

\begin{abstract}
Mesmo os dois terços deles com algum contato com a religião tinham uma exposição muito mais minimalista do que as gerações anteriores. Para muitos, tinha sido, no máximo, participação nos "feriados". Diferentemente dos entrevistados da Geração Silenciosa ou Baby Boomer - e mais ainda os da geração X - quase nenhuma dessas pessoas procurou a religião convencional por conta própria depois disso. No entanto, muitas também não procuraram alternativas espirituais. Isso foi bem diferente das gerações anteriores (MERCADANTE, 2014, p. 46-47).
\end{abstract}

Uma vez que os nones ${ }^{4}$ não têm nem mesmo uma categoria "espiritual", o que é a igreja afinal? Quando um total de " $25 \%$ a $30 \%$ das pessoas, na casa dos vinte e poucos anos, hoje afirma que não tem afiliação religiosa - cerca de quatro vezes mais do que em qualquer geração anterior” (PUTNAM; CAMPBELL, 2010) - este cenário demanda sérias considerações de qualquer equipe pastoral ao planejar cultos durante a fase da covid-19.

Uma análise cuidadosa de 95 entrevistas com judeus e cristãos (vários grupos denominacionais protestantes, evangélicos e católicos), incluindo seekers ${ }^{5}$ e nones de Boston e Atlanta, reali-

\footnotetext{
4 Nones se refere ao grupo de pessoas que não são afiliados a nenhuma religião. Normalmente se consideram espirituais, mas não religiosos.

5 Seekers se refere ao grupo de pessoas que estão numa jornada espiritual caracterizada pela constante busca. Trocam as certezas e absolutismos pela provisional e prático.
} 
zadas por Nancy T. Ammerman e publicadas em 2013, descobriu quatro categorias de ideologias religiosas entre os participantes. Uma coluna paralela apresenta como 1 Coríntios 13:8 pode ser colocado em diálogo interseccional com as categorias de igreja de Ammerman (2013, p. 258).

\begin{tabular}{l|l}
$\begin{array}{l}\text { Espiritualidades teístas e não-teístas } \\
\begin{array}{l}\text { a. Espiritualidade teísta: conecta espiritualidade às divin- } \\
\text { dades pessoais. }\end{array}\end{array}$ & $\begin{array}{l}\text { Prioriza geralmente línguas e experiências pessoais como } \\
\text { principais definidores da vida religiosa (dimensão pessoal } \\
\text { acima da comunidade). }\end{array}$ \\
\hline $\begin{array}{l}\text { b. Espiritualidade extrateísta: localiza a espiritualidade em } \\
\text { vários focos naturalistas de transcendência. }\end{array}$ & $\begin{array}{l}\text { Prioriza geralmente as profecias e a onisciência de Deus e } \\
\text { a onipresença do poder como definidor final da verdade e } \\
\text { da igreja. }\end{array}$ \\
\hline $\begin{array}{l}\text { c. Espiritualidade ética: concentra-se na compaixão } \\
\text { cotidiana. }\end{array}$ & $\begin{array}{l}\text { Geralmente prioriza o amor como uma abordagem normati- } \\
\text { va para definir tudo e excluir o que está errado. }\end{array}$ \\
\hline $\begin{array}{l}\text { d. Espiritualidade de crença e pertencimento: ligados a } \\
\text { noções culturais de religiosidade. }\end{array}$ & $\begin{array}{l}\text { Prioriza geralmente o conhecimento da doutrina bíblica, } \\
\text { pureza do credo e clareza de crença }\end{array}$ \\
\hline & “0 amor nunca perece; mas as profecias desaparecerão, as \\
& línguas cessarão, o conhecimento passará" (1Co 13:8, NVI)
\end{tabular}

A conclusão principal do estudo de Ammerman (2013) é que a textura complexa e as manifestações de crenças e afiliações institucionais ou a falta delas define os participantes em potencial de qualquer experiência de adoração. Ou, como Ammerman descreve, a divisão ideológica - "entre espiritualidade e religião é muito mais porosa do que a moral e política" - visões políticas estão guiando ideologias religiosas e não o contrário (AMMERMAN, 2013, p. 258). Tais distinções também podem ser percebidas no diálogo das categorias de profecias, línguas e conhecimentos com o amor, conforme 1 Coríntios 13.

Putman e Campbell (2010) argumentam que a relação entre crença e não-crença reflete a observação de que "a associação entre religião e política pode ter sido o mais forte fator isolado para essa mudança avassaladora” (PUTMAN; CAMPBELL, 2010) de afiliados se tornarem não-afiliados. Assim, eles consideram que as "previsões quanto ao desaparecimento da religião nos Estados Unidos são prematuras" (PUTMAN; CAMPBELL, 2010). Para eles, o mais provável seria que "um número crescente de jovens americanos rejeita a doutrina religiosa que é política ou intolerante demais para o seu gosto, líderes religiosos inovadores irão aceitar ofertas mais palatáveis" (PUTMAN; CAMPBELL, 2010).

Nesse sentido, a GCC parece bem posicionada. A missão da igreja é expressa na seguinte frase: "Desejamos revelar o esplendor de Cristo e afirmar o valor de todas as pessoas" (ABOUT, 2019, online). Uma igreja que está aberta a afirmar tudo sem negar as raízes de suas doutrinas e sua distinção é inimaginável para muitos.

A espiritualidade, portanto, não é um fenômeno individualizado e difuso, nem uma alternativa cultural única à "religião". A análise das avaliações contestadas da Crença e Espiritualidade Pertencente permite um vislumbre sobre o "trabalho de fronteira moral" sendo feito através da identificação como "espiritual, mas não religioso" (AMMERMAN, 2013, p. 258). 


\section{Projeto online da GCC durante a pandemia de covid-19 - uma variedade de abordagens}

Ser igreja durante a pandemia de covid-19 exigiu mudanças e adaptações rápidas, e a GCC desenvolveu um plano. Inicialmente eu era o único defensor das reuniões de culto através do aplicativo Zoom, e essa ideia foi, a princípio, ignorada pela equipe da GCC: "Os membros da igreja querem ver o prédio e ouvir o órgão sendo tocado pelo irmão Kemp" - disse um líder; e ele estava correto. Depois de começar uma transmissão rudimentar, com apenas uma câmera, a igreja mudou para uma produção no YouTube Live com três equipamentos. Não havia tempo nem disposição para realizar uma pesquisa a fim de determinar o que era mais útil; em vez disso, se improvisou com uma abordagem baseada em três iniciativas:

1. Destacar o icônico cenário arquitetônico do edifício da GCC como um recurso central das transmissões todos os sábados. Para essa abordagem, as três câmeras se provaram ser importantes, bem como a experiente equipe de audiovisual. Passou-se a incluir close-ups do funcionamento interno do órgão, como os pedais e alavancas. Também foram incluídas duas tomadas pela câmera do alto-falante e tomadas intercaladas das janelas redondas com seus vitrais.

2. Fornecer uma "recepção após o culto" regularmente para as pessoas, compartilhando questões da vida cotidiana, pedidos de oração e testemunhos. Existe um efeito interessante nesse compartilhamento de experiências e na oportunidade de ver os rostos uns dos outros, o que fortalece a humanidade e as conexões de parentesco entre os membros da "tribo" da GCC. O apoio tribal ficou particularmente evidente quando um membro perguntou sobre "como marcar uma consulta com um optometrista". E antes que a chamada de Zoom terminasse, tínhamos um membro optometrista da GCC oferecendo uma oportunidade de consulta para o membro em necessidade.

3. Promover uma variedade de atividades lideradas e executadas por membros, incluindo:

a. Reunião do grupo Living Project antes do culto de sábado, pelo Zoom. Esse encontro é sempre emocionante. Saber que é possível expressar crenças e dúvidas sem ser julgado como herege ou, ainda pior, receber um olhar de "como pode ser tão burro!";

b. Reunião do grupo Survive \& Thrive, às quartas-feiras, pelo Zoom, relacionada à covid-19, com especialistas respondendo perguntas e fornecendo acesso a recursos confiáveis, científicos e médicos;

c. Reunião do grupo Prayer \& Study, às quintas-feiras, pelo Zoom, com especialistas bíblicos que não estariam tão prontamente disponíveis em um mundo físico;

d. Série de concertos Glendale Noon, no canal do YouTube da GCC, um programa contínuo que a igreja sempre realizou no santuário, todas as quartas-feiras; 
e. Culto em espanhol no sábado de manhã, antes do culto regular em inglês, transmitido pelo YouTube e pelo Facebook. A GCC passou a alcançar pessoas em outro idioma com a sua ideologia receptiva para outras convicções religiosas;

f. Os cultos armênios e romenos também adotaram seu próprio formato.

Está a GCC fazendo alguma diferença através dessas novas maneiras de ser igreja?

\section{Como avaliar o impacto dessas opções online?}

Sabe-se, há algum tempo, que a igreja não é um conjunto de doutrinas, nem um edifício, nem mesmo o agregado de extensões institucionais locais, estaduais, nacionais e internacionais. Igreja são os encontros locais de crentes e seguidores de Jesus, que se reúnem para apoiar uns aos outros e proclamar seu amor por Cristo ao amarem de forma sistemática aqueles que estão ao redor - os ainda-não-crentes - incluindo os irmãos e irmãs que foram feitos de "de modo especial e admirável" (Sl 139:14, NVI) pelo Deus criador.

O mundo cristão pós-cristandade pode ser dividido em dois campos. Um lado acolhedor, que imagina que todos pertencem uns aos outros, e vê o mundo a partir da perspectiva da criação através do Calvário com um final na família da Nova Jerusalém. E o outro lado, que tem uma visão mais restrita; uma visão dos direitos exclusivos de acesso à redenção. Somente ser membro da instituição correta pode dar ao crente acesso às recompensas e privilégios de Deus. Na tabela abaixo há explicações e o porquê de essas duas compreensões exigirem mudança durante a pandemia da covid-19 e depois dela.

\begin{tabular}{|c|c|c|c|}
\hline Comunhão & Visão de Mundo & Mensagem & Afiliação \\
\hline $\begin{array}{l}\text { Comunhão aberta } \\
\text { Todos são bem-vindos } \\
\text { a participar da Ceia do } \\
\text { Senhor (cada participante } \\
\text { avalia sua condição de } \\
\text { participação). }\end{array}$ & $\begin{array}{l}\text { Inclusiva } \\
\text { Todos os que desejam } \\
\text { se tornar membros e ser } \\
\text { batizados, aceitando a } \\
\text { Bíblia como credo, são } \\
\text { bem-vindos. }\end{array}$ & $\begin{array}{l}\text { Mensagem cristocêntrica } \\
\text { Enfatiza o ministério } \\
\text { e a vida de Jesus, seu } \\
\text { ministério atual por meio do } \\
\text { Espírito de Cristo (Espírito } \\
\text { Santo) e a segunda vinda } \\
\text { como solução final, enquan- } \\
\text { to trabalhamos na Terra, } \\
\text { construindo o reino divino } \\
\text { de amor. }\end{array}$ & $\begin{array}{l}\text { Autodesignada } \\
\text { A afiliação é focada em sua } \\
\text { natureza voluntária e no } \\
\text { compromisso de trabalhar } \\
\text { para mudar a nós mesmos } \\
\text { e o mundo. } 0 \text { compromisso } \\
\text { das pessoas é tomado } \\
\text { como norma de inclusão. }\end{array}$ \\
\hline $\begin{array}{l}\text { Comunhão fechada } \\
\text { Somente membros } \\
\text { julgados pelos oficiais da } \\
\text { mesa da comunhão como } \\
\text { estando em boas condições } \\
\text { podem participar. }\end{array}$ & $\begin{array}{l}\text { Exclusiva } \\
\text { Somente aqueles que } \\
\text { aceitam as definições } \\
\text { específicas de crenças e } \\
\text { doutrinas da igreja podem } \\
\text { ser aceitos como membros. }\end{array}$ & $\begin{array}{l}\text { Doutrinária } \\
\text { A afirmação e a adesão } \\
\text { franca a crenças específi- } \\
\text { cas são o sinal de afiliação } \\
\text { e a total conformidade é o } \\
\text { único caminho para se filiar }\end{array}$ & $\begin{array}{l}\text { Centralizada e hierárquica } \\
\text { Os títulos são essenciais } \\
\text { para manter a estrutura } \\
\text { institucional hierárquica } \\
\text { da igreja; todos devem agir } \\
\text { de acordo com as funções } \\
\text { atribuídas. }\end{array}$ \\
\hline
\end{tabular}

A chave do ministério na GCC é a total transparência quanto à fragilidade humana subordinada a uma aceitação completa da redenção que o Senhor proveu para todos. Acrescentado a isso, um conjunto de atitudes sem julgamento que reconhecem que todos fracassam, ao mesmo 
tempo em que se mobilizam pelo serviço e pela adoção total da vulnerabilidade pessoal e coletiva - guiados pelo Parakletos na realização da justiça, verdade e serviço.

Mas o Conselheiro, o Espírito Santo, que o Pai enviará em meu nome, lhes ensinará todas as coisas e lhes fará lembrar tudo o que eu lhes disse. Deixo-lhes a paz; a minha paz lhes dou. Não a dou como o mundo a dá. Não se perturbem os seus corações, nem tenham medo. Vocês me ouviram dizer: Vou, mas volto para vocês. Se vocês me amassem, ficariam contentes porque vou para o Pai, pois o Pai é maior do que eu (Jo 14:26-28, NVI).

Somente Jesus, em sua segunda vinda, separará o joio do trigo - esse não é o trabalho da igreja. Esta deve procurar servir e evitar julgar. Ensinar e evitar a doutrinação. Buscar amar e evitar pretensões humilhantes e/ou engrandecedoras de especial favor para Deus. Mas mesmo esses padrões ainda exigem um certo sucesso para os cultos da igreja.

Avaliar o ministério online já era uma tarefa preocupante para a GCC. O pastor tentou estabelecer presença online quando começou o seu ministério ali e falhou. O número de participantes é a maneira de julgar o sucesso do nosso culto? Não tendo maneiras viáveis de "contar a presença" além de estimativas aproximadas, não se deveria argumentar com base na "presença". Em vez disso, talvez uma opção mais tangível seria mais adequada.

Toda semana, ofertas locais e dízimos são coletados em todas as igrejas denominacionais; e representam o fôlego de vida institucional da sobrevivência econômica. E isso é bem monitorado. Um relatório financeiro recente da Associação do Sul da Califórnia, da Igreja Adventista do Sétimo Dia, destacou três fatos que são chave para a "avaliação" online da GCC: (1) o total de dízimos que a Associação recebeu diminuiu em 20\%; (2) o total de dízimos enviados pela GCC para a Associação, referente a abril de 2020, cresceu 7\%; e (3) as ofertas e pactos destinados à igreja local permaneceram nos mesmos níveis dos meses anteriores. ${ }^{6}$

É necessário manter firme as convicções de que o que a missão da igreja tem um papel no cosmos da adoração online. Há mais do que opções online de culto como estratégia de uma atuação bem sucedida da igreja durante e após a pandemia da covid-19. Quatro outros exemplos devem ser mencionados:

1. A presença contínua da equipe da igreja por meio da ajuda administrativa de um secretário/tesoureiro ativo. Há uma secretária atendendo pessoalmente o telefone da igreja (a partir da sua casa).

2. A visitação por parte da equipe pastoral para pessoas em quarentena. Esta é combinada com a oferta de empréstimo de dispositivos eletrônicos (tablets) para aqueles que precisam de ajuda para acompanhar os programas da igreja pelo YouTube e Zoom.

3. Depois de dividir as informações dos contatos telefônicos de todos os membros, uma agenda semanal de ligações foi estabelecida.

\footnotetext{
6 Dois detalhes devem ser registrados. Primeiro, foram recebidas ofertas extraordinárias que não eram esperadas de doadores não regulares. Em segundo lugar, há dificuldade para manter as ofertas locais.
} 
4. Uma carta personalizada, assinada pelo pastor sênior, foi enviada a todos os membros da igreja, incluindo - como era de se esperar - um envelope de ofertas e instruções sobre como doar online.

5. A revista da igreja, além de estar disponível online, também tem sido impressa mensalmente e enviada por correio para aqueles que preferem uma cópia impressa.

Certamente ainda há muito para a equipe e os voluntários da GCC aprenderem sobre como servir a família da igreja durante um período de pandemia e de quarentena. Ajudar a entender como servir melhor a sua comunidade vem da própria comunidade.

\section{Qual é o futuro da GCC e das demais igrejas?}

Os mais pessimistas imaginam que o ser humano pós-pandemia não será muito diferente de antes. Um olhar otimista, no entanto, identifica oportunidades. Talvez a maior oportunidade disponível seja a de reavaliar crenças e valores.

Se, por um lado, neste período de confinamento, muitas pessoas passaram a ter mais tempo para recuperar projetos e passatempos esquecidos, enfrentar desafios pessoais e refletir sobre decisões e relacionamentos, inclusive espirituais; por outro lado, pastores e líderes religiosos também têm a oportunidade de refletir sobre compreensões eclesiásticas fundamentais. Em tempos de crise, quando as facilidades e confortos não estão mais disponíveis, existe a possibilidade de se redescobrir a essência.

Estudiosos têm observado que cada geração é marcada por uma crise. Baby boomers foram marcados pela guerra do Vietnã, a geração X pela epidemia da AIDS e a geração Y (ou a geração do milênio) pelo ataque terrorista de 11 de setembro de 2001 e pela crise econômica de 2008 . Agora, os estudiosos apontam que a pandemia do coronavírus será definidora para a Geração Z (aqueles que nasceram depois do ano 1995). As possíveis influências da crise no desenvolvimento desses jovens serão: um posicionamento político mais independente, um sentido de inclusivismo mais aguçado e uma atitude ainda mais empreendedora e criativa. Finalmente, essa geração será ainda mais interessada em voluntariado do que a Geração Y (WHITE, 2020b).

No entanto, tudo isso continuará acontecendo num espaço social diferente. As gerações Z (idades entre 12 e 25 anos) e alpha (até 11 anos) nasceram em um mundo digital. Nunca viram o mundo sem a presença de computadores e celulares. A tecnologia é uma extensão de sua forma de conhecer e se relacionar com o mundo. E, para elas, o contexto social é formado pelas dimensões presencial e virtual como uma só realidade. Afinal, as mídias sociais não são um lugar só para compartilhar informação, mas acima de tudo para ser social.

A realização de cultos pela internet talvez tenha sido a mudança mais emblemática da religiosidade durante a pandemia. Nos Estados Unidos, uma pesquisa apontou que enquanto 91\% das igrejas fechou os templos para o público, mais de $80 \%$ dos cristãos assíduos indicaram que sua igreja está oferecendo cultos pela internet ou pela TV e 57\% desses adultos estão assistindo à programação dessa forma devido à pandemia do coronavírus (GECEWICZ, 2020).

As estatísticas mais recentes pré-pandemia, no entanto, já revelavam que, nos Estados Unidos, mais da metade dos cristãos da geração Y se divide entre os cultos presenciais e pela internet. 
Além disso, o ambiente virtual também é propício para a missão. Jovens cristãos postam conteúdo religioso (44\%) e conversam sobre espiritualidade na internet (41\%) (HOW, 2013, online).

A reflexão sobre a pandemia evidenciou que não é suficiente dar tempo e colocar as pessoas juntas. A maior consciência do coletivo exige orientação sobre o que fazer e como lidar com os relacionamentos sob a epistemologia bíblica do amor. A igreja tem potencial de orientar na educação de filhos, relacionamentos conjugais e, principalmente, na comunhão com Deus. O cristão, especialmente, tem a solidariedade como parte da sua identidade. Há expectativa de que, ao redescobrir a alegria e o sentido de uma vida de serviço, muitos continuem vivendo assim. Esses momentos de envolvimento na missão podem ser transformadores!

Como White (2020a) observa, as igrejas têm sido forçadas a mudar de uma abordagem centrada na multidão no final de semana, para uma abordagem "encarnacional" nos sete dias da semana; a estar presentes na internet; a adotar as mídias sociais; a inovar e mudar; e a voltar o seu foco para a missão. E essas são cinco maneiras que a pandemia pode estar ajudando a salvar a igreja.

As pessoas têm descoberto que não devem escolher entre falar de Jesus e demonstrar o Seu amor, entre servir e salvar. Não têm que equilibrar boas ações com a proclamação do evangelho - porque as duas dimensões são partes indivisíveis da mesma moeda. Mobilizações em prol de pessoas em vulnerabilidade devido ao aumento na desigualdade social por meio de formas de socorro e proteção, inclusive financeiras, serão importantes no contexto pós-pandemia.

\footnotetext{
Vários futuristas internacionais dizem que o coronavírus funciona como um acelerador de futuros. [...] Outras mudanças estavam mais embrionárias e talvez não fossem tão perceptíveis ainda, mas agora ganham novo sentido diante da revisão de valores. [...] Como exemplos, podemos citar o fortalecimento de valores como solidariedade e empatia (MELO, 2020, online).
}

O momento é fundamentalmente importante para uma decisão: resgatar as crenças e fazer mudanças significativas ou simplesmente preservar o status quo?

\section{Referências}

ABOUT Our Church. Glendale City Church, 2019. Disponível em: $<$ https://bit.ly/3aTR7lJ $>$. Acesso em: 07 jul. 2020.

AMMERMAN, N. T. Spiritual but Not Religious? Beyond Binary Choices in the Study of Religion. Journal for the Scientific Study of Religion, v. 52, n. 2, p. 258-278, jun. 2013.

BRANSON, M.; MARTINEZ, J. F. Churches, Cultures and Leadership: A Practical Theology of Congregations and Ethnicities, Westmont: IVP Academic, 2011. E-book.

CROUCH, A.; KEILHACKER, K.; BLANCHARD, D. Leading Beyond the Blizzard: Why Every Organization Is Now a Startup. The Praxis Journal, 20 mar. 2020. Disponível em: <https://bit. ly/3lek80d>. Acesso em: 7 jul. 2020.

GECEWICZ, C. Few Americans say their house of worship is open, but a quarter say their faith has grown amid pandemic. Pew Research Center, 30 abr. 2020. Disponível em: <https://pewrsr. ch/2FJyG7F>. Acesso em: 9 jul. 2020. 
HOW Technology is Changing Millennial Faith. Barna, 15 out. 2013. Disponível em: <https://bit. ly/2YwQ4Mh>. Acesso em: 9 jul. 2020.

JEFFERY, A. See Religions Around the World Adapt in the Age of Coronavirus. CNBC, 10 abr. 2020. Disponível em: <https://cnb.cx/3j7Y4T5>. Acesso em: 13 jul. 2020.

KIM, G. J.; SHAW; SUSAN, M. Intersectional Theology. Minneapolis, MN: Fortress Press, 2018.

MELO, C. Como o coronavírus vai mudar nossas vidas: dez tendências para o mundo pós-pandemia. El País, 13 abr. 2020. Disponível em: <https://bit.ly/3gwQjoc>. Acesso em: 9 jul. 2020.

MERCADANTE, L. A. Belief without Borders. Oxford, UK: Oxford University Press, 2014.

PUTNAM, R. D.; CAMPBELL, D. E. Walking Away from Church. Los Angeles Times, 17 out. 2010. Disponível em: <https://lat.ms/34tNiTd>. Acesso em: 7 jul. 2020.

SPICKARD, J. V. Alternative Sociologies of Religion. New York: NYU Press, 2017.

STEINMETZ, K. She Coined the Term 'Intersectionality' Over 30 Years Ago. Here's What It Means to Her Today. Time, 20 fev. 2020. Disponível em: <https://bit.ly/3hqjuu1>. Acesso em: 13 jul. 2020.

WHITE, J. E. 5 Ways the Pandemic Is Saving the Church. Church\&Culture, 20 abr. 2020. Disponível em: <https://bit.ly/31ntmPF>. Acesso em: 09 jul. 2020a.

. Covid-19 and Generation Z. Crosswalk, 13 abr. 2020. Disponível em: <https://bit. ly/2QixtGF>. Acesso em: 07 jul. 2020 b.

WILlimON, W. H. Corpus Christi: Carnal Thoughts on a Spiritual Day. The Christian Century, 3-10 jun. 1981. 